\title{
Wisseling van accountantskantoor; een fata morgana in de toekomst?
}

\author{
Drs. H.P.A.J. Langendijk
}

\section{Inleiding ${ }^{1}$}

Het accountantsberoep wordt tegenwoordig geconfronteerd met een stijgende belangstelling, die vaak een kritische ondertoon heeft. Deze kritiek richt zich vooral op de onduidelijkheid van de accountantsverklaring, de rol van de accountant bij déconfitures en fraudes en tevens de 'value for money' die de accountant aan de onderneming(sleiding) levert. Eigenlijk kan gesteld worden dat de controlerende accountant het maatschappelijk verkeer tot op heden nog onvoldoende duidelijk kan maken wat nu exact zijn functie omvat. Hierbij dient wel aangetekend te worden dat uit het onderzoek van het Limperg Instituut (1987, p. 77) blijkt dat de (controle)functie van de accountant allerwege van groot belang wordt geacht.

In dit artikel wordt gepoogd om zowel op theoretische als op empirische gronden een verklaring te verschaffen voor het wisselen van accountantskantoor. Daartoe zal om de primaire functie van de accountant te verduidelijken eerst worden weergegeven waardoor de controlerende functie is ontstaan. Hierbij wordt gebruik gemaakt van de 'agency theory', welke wordt toegepast op de rol van de controlerende accountant (Jensen en Meckling, 1976; voor Nederland, Langendijk, 1989). Daarna wordt kort weergegeven wat de redenen kunnen zijn om een bepaald accountantskantoor te kiezen. Vervolgens wordt ingegaan op redenen om van accountantskantoor te wisselen of om dat juist niet te doen. In het verlengde hiervan zullen enkele empirische resultaten worden gepresenteerd waaruit blijkt dat het wisselen van accountantskantoor door grote ondernemingen in Nederland niet veel voorkomt. Voorts wordt het wisselen van accountantskantoor behandeld in het licht van de (aanhoudende) fusiegolf van accountantskantoren in Nederland.

\section{Het ontstaan van het accountantsberoep}

Het zelfstandige accountantsberoep is feitelijk tot ontwikkeling gekomen aan het einde van de $19 \mathrm{e}$ eeuw. Door Belle (1961, p. 11-17) worden met name als ontstaansoorzaken van een afgesplitste, zelfstandige controlefunctie in Nederland genoemd de Pincoffsaffaire (fraude) en de scheiding tussen eigendom en leiding die zich in dat tijdsgewricht voltrekt door de groei van het aantal NV's en het groter worden van deze ondernemingen. Door deze scheiding van eigendom en leiding ontstaan geleidelijk tegenstrijdige belangen tussen managers en aandeelhouders en tevens tussen bijvoorbeeld managers en vreemdvermogenverschaffers.

In het kader van de 'agency theory' worden de aandeelhouders als opdrachtgever (principaal) beschouwd en de manager als agent gezien. De manager (agent) verricht werkzaamheden c.q. neemt beslissingen in opdracht van de aandeelhouders (principaal). Een groot probleem hierbij is de zogenaamde informatie-asymmetrie. Er is sprake van informatie-asymmetrie indien de manager (agent) de beschikking heeft over cruciale informatie omtrent zijn eigen 'performance' en

Drs. H. P. A. J. Langendijk studeerde bedrijfseconomie aan de Universiteit van Amsterdam, doctoraal examen 1976. Vervolgens een aantal jaren in de accountancy werkzaam geweest. Momenteel universitair hoofddocent Externe verslaggeving aan de Universiteit van Amsterdam, vakgroep Accountancy. 


\section{MAB}

de aandeelhouders (principaal) niet in de gelegenheid zijn om de functie-uitoefening van de manager waar te nemen of (directe) toegang te hebben tot de desbetreffende informatie. Een potentieel risico is dat de manager op basis van het feit dat hij de beschikking heeft over.superieure informatie beslissingen zal nemen die zijn belangen maximaliseert ten koste van de belangen van de aandeelhouders (en andere groeperingen).

In het kader van de 'agency theory' wordt dit risico het 'moral hazard' probleem genoemd. Door dit 'moral hazard' probleem ontstaat de gerede mogelijkheid dat de manager (agent) niet altijd zijn werkzaamheden verricht in overeenstemming met de belangen van de aandeelhouders (principaal) hetgeen leidt tot 'agency' kosten. Dit 'moral hazard' probleem en de daaruit voortvloeiende 'agency' kosten kunnen worden verminderd door de belangen van de manager meer parallel te laten lopen met de belangen van de aandeelhouders door bijvoorbeeld de tantièmes te koppelen aan de gepresenteerde nettowinst in de winst- en verliesrekening. Voorts kan het desbetreffende probleem grotendeels worden opgelost door het verschaffen van informatie, waardoor de aandeelhouders de prestaties van de manager adequaat kunnen beoordelen. Voor beide oplossingen van het 'moral hazard' probleem is het noodzakelijk dat de door het management verstrekte informatie juist en volledig is. Als resultante is een behoefte ontstaan (en gegroeid) aan een onafhankelijk en zelfstandig accountantsberoep om een keurmerk af te geven ten aanzien van de door het management verstrekte informatie, in casu veelal de jaarrekening annex jaarverslag.

In de terminologie van de 'agency' theory is accountantscontrole een middel om de 'agency' kosten te verminderen.

\section{De keuze van accountantskantoor}

Voortbordurend op de uitgangspunten van de 'agency' theorie kan gesteld worden dat managers een accountantskantoor kiezen c.q. voordragen dat naar verwachting zal gaan voldoen aan de behoefte aan zekerheid van de aandeel- houders. Aandeelhouders verwachten dat managers een accountantskantoor kiezen c.q. voordragen dat een accountantscontrole van hoge kwaliteit levert.

Ofschoon verschillen in kwaliteit tussen accountantskantoren ten aanzien van hun kernactiviteit de accountantscontrole moeilijk te meten zijn, is in de Angelsaksische literatuur toch een tweetal theorieën ontwikkeld om verschillen in kwaliteit van accountantskantoren ten aanzien van de controle, te verklaren.

De eerste theorie (DeAngelo, 1981, p. 115) gaat uit van de premisse dat de ex ante waarde van een accountantscontrole voor een consument van deze diensten (aandeelhouders, crediteuren enzovoort) afhankelijk is van (1) het vermogen van een controlerend accountant om (materiële) fouten in en/of inbreuken op het gehele administratieve en financiële systeem te ontdekken en (2) het vermogen om de druk van de zijde van de cliënt (management) te weerstaan om eventueel geconstateerde fouten c.q. inbreuken niet in de openbaarheid te brengen. Voorts wordt door DeAngelo verondersteld dat een accountantskantoor, dat al een aantal jaren een bepaalde cliënt controleert, gebaat is bij het continueren van deze relatie. De redenen daarvoor zijn dat de kosten om de controle bij deze cliënt op te starten in het (verre) verleden al zijn gemaakt en nu over een langere periode goedgemaakt kunnen worden en dat 'know-how' ten aanzien van de (administratieve) organisatie van de cliënt is opgebouwd hetgeen kostenverlagend werkt. Beide factoren kunnen leiden tot een voordelige marge op de controlewerkzaamheden voor het desbetreffende accountantskantoor zowel nu als in de toekomst. DeAngelo spreekt in dit kader over 'quasi rents'. Daar grote accountantskantoren meer cliënten hebben, zetten zij meer specifiekcliënt gerelateerde voordelen op het spel, indien bekend raakt dat zij een controleprodukt leveren dat onder de maat is. Dit blijkt onder meer indien in de publiciteit komt dat de controle niet adequaat is uitgevoerd (fraude met materiële consequenties voor het getoonde vermogen en resultaat niet gesignaleerd) of dat door een bepaalde handelwijze van een accountant van een kantoor de onafhankelijkheid in twijfel wordt getrokken. 


\section{MAB}

Feitelijk dienen deze cliënt-specifieke voordelen die een bepaald accountantskantoor bezit als 'onderpand' voor een hoog niveau van accountantscontrole en een grote mate van onafhankelijkheid. Ceteris paribus geredeneerd, is volgens DeAngelo de grootte van het accountantskantoor een surrogaat voor de in de praktijk moeilijk waar te nemen c.q. te meten kwaliteit van de accountantscontrole. Eenvoudig gezegd, hoe groter het accountantskantoor hoe beter de kwaliteit van een accountantscontrole.

De tweede theorie (Klein, Crawford en Alchian, 1978) stelt dat accountantskantoren permanent moeten investeren in de 'brand name' van hun kantoor. Deze naam en faam van het accountantskantoor moet ontwikkeld en onderhouden worden. Door de reputatie van het accountantskantoor op een hoog niveau te houden kunnen voordelen behaald worden. Volgens hun theorie dient in eerste instantie een (goede) reputatie opgebouwd te worden. Daarna kan op basis van deze (goede) reputatie een hoge, kwaliteitverzekerende prijs voor het controleprodukt in rekening worden gebracht. Deze prijs is veelal hoger dan de prijs die in rekening gebracht dient te worden om een verantwoorde controle nog kostendekkend te kunnen verzorgen. Hieruit volgt dat er geen prikkels zijn om een produkt te leveren dat niet van hoge kwaliteit is, daar in het laatste geval de reputatie van het accountantskantoor wordt beschadigd en de extra prijsmarge kan worden verspeeld zowel nu als in de toekomst.

Klein en Leffler (1981, p. 634) concluderen, voortbouwend op deze analyse, dat consumenten van gecontroleerde jaarrekeningen de hoogte van de prijs van de controle kunnen hanteren als indicator van kwaliteit. In de accountantsbranche worden in de USA de Big Eight accountantskantoren beschouwd als degene met een 'brand name' (reputatie) (AICPA, 1980; Dopuch en Simunic, 1980; Palmrose, 1988). Bovenstaande conclusie van Klein en Leffler wordt gestaafd door een groot aantal empirische onderzoeken in de USA en Australië waaruit blijkt dat Big Eight kantoren significant hogere prijzen in rekening brengen voor de controle dan niet-Big Eight kantoren (Francis en Simon, 1987; voor de Australische markt zie Francis, 1984).
Bij vergelijking van de twee theorieën komt naar voren dat DeAngelo een micro-economisch vertrekpunt ('agency' theorie) heeft en Klein e.a. een markt c.q. marketing benadering hebben voor de keuze van accountantskantoor en beoordeling van het controleprodukt. Beide theorieën tenderen naar dezelfde conclusie dat grote(re) accountantskantoren een controleprodukt van een hogere kwaliteit leveren. ${ }^{2}$

De gedachten van DeAngelo hebben echter een hechter theoretisch fundament. Haar analyses zijn in tegenstelling tot de analyses van Klein e.a. uitgebreid onderbouwd vanuit de micro-economie in het bijzonder de 'agency' theorie. De gedachtenvorming van Klein e.a., alhoewel nuttig en interessant, mist deels een dergelijke wetenschappelijke ondergrond.

\section{Wisseling van accountantskantoor}

Het wisselen van accountantskantoor door ondernemingen is een fenomeen dat om een verklaring vraagt. In de Angelsaksische literatuur wordt hieraan, in tegenstelling tot de Nederlandse vakliteratuur, dan ook al vele jaren aandacht besteed.

Terecht wordt door Schilder in zijn oratie genaamd 'Onderzoekt alles' aangestipt dat wisseling van accountantskantoor en de gronden waarop cliënten accountantskantoren selecteren interessante onderzoekthema's zijn (1989, p. 11). Door Williams (1988, p. 247-248) wordt een drietal groepen van redenen onderscheiden om van accountantskantoor te wisselen:

1 de veranderingen in de contractuele relaties bij een cliënt;

2 de efficiency van het accountantskantoor; 3 de reputatie van een cliënt.

ad 1 De veranderingen in de contractuele relaties bij een cliënt

Een van de uitgangspunten van de 'agency theory' is dat organisaties een knooppunt van contracten zijn. Een wisseling van accountantskantoor kan het gevolg zijn van een verandering in de contracten tussen de aandeelhouders/eigenaren en het management. Nieuwe contracten tussen aandeelhouders/eigenaren en management 


\section{MAB}

worden veelal afgesloten indien de cliënt wordt overgenomen door een andere onderneming of als een nieuwe manager (of controller) wordt aangenomen.

Wanneer een belangrijke mutatie optreedt in het management van een cliënt kunnen de nieuwe directieleden verzoeken om een wisseling van accountantskantoor omdat de huidige accountant een sterke band heeft met het oude management of omdat het nieuwe management op deze wijze eens wat frisse ideeën hoopt binnen te halen.

Tevens is het mogelijk dat het nieuwe management een accountantskantoor vraagt waarmee zij in het verleden goede ervaringen heeft opgedaan.

\section{ad 2 De efficiëntie van het accountantskantoor}

Uit onderzoek in de USA blijkt dat het belangrijkste criterium om voor een bepaald accountantskantoor te kiezen zijn naam en faam als controleur is (Deloitte, Haskins and Sells, 1978). Dit onderzoek legt een link tussen reputatie (competentie) en efficiëntie. Het is logisch dat een onderneming kiest voor een accountantskantoor dat als efficiënt bekend staat. Als grove indicatie van de mate van efficiëntie van een accountantskantoor kan de omzet per werknemer in guldens worden gehanteerd. Deze verschilt aanzienlijk per accountantskantoor in Nederland. ${ }^{3}$

Voorstelbaar is dat een cliënt van accountant wisselt omdat een ander accountantskantoor de controle- en adviesdiensten (op termijn) significant goedkoper kan verrichten en wellicht tevens betere kwaliteit kan leveren. Deze wisseling kan mede ingegeven zijn door het feit dat enige onvrede bestaat bij de cliënt omdat deze weinig inzicht heeft in de inhoud en strekking van de diensten die door een accountant worden verricht en het daarbij horende aantal uren annex tarief. ${ }^{4}$

De mate van efficiency van een accountantskantoor kan voorts gerelateerd worden aan de specialisatie van accountantskantoren naar bedrijfstak en wel om twee redenen:

- specialisatie per bedrijfstak leidt tot schaalvoordelen omdat de kennis van de werkomgeving van de cliënten wordt vergroot;

- specialisatie leidt tot aanbieding van een hoog niveau van controle- en adviesdiensten omdat een grote kennis van de bedrijfstak aanwezig is.

In Nederland is bijvoorbeeld KPMG sterk vertegenwoordigd in het bankwezen en Moret Ernst \& Young in de verzekeringsbranche.

Overigens hebben de grote maatschappen in Nederland vaak teams die specifiek de cliënten in bepaalde bedrijfstakken controleren. Op deze wijze wordt ook specialisatie gerealiseerd.

Grote (en ook middelgrote) ondernemingen zijn in Nederland voor een adequate controle en advisering de facto aangewezen op een groot accountantskantoor. Door de fusiegolf in Nederland komen daarvoor nog maar vier accountantskantoren (KPMG, Moret Ernst \& Young, Coopers \& Lybrand Dijker van Dien en de TRN Groep) in aanmerking. ${ }^{5}$ Ter indicatie: bijna $90 \%$ van de in Amsterdam ter beurze genoteerde ondernemingen wordt gecontroleerd door deze vier kantoren. Specialisatie naar bedrijfstak, werken met teams van bedrijfstakspecialisten c.q. uitbreiding van de omvang van het accountantskantoor kan de efficiency van een accountantskantoor zeker vergroten.

De laatstgenoemde ontwikkeling heeft echter ook haar schaduwzijde. Het wisselen van accountantskantoor wordt voor grote cliënten lastig, omdat over het algemeen nog slechts drie alternatieven in Nederland aanwezig zijn.

De fusiegolf lijkt in Nederland dan ook wat te zijn afgenomen. De voorgenomen fusie tussen Deloitte Dijker Van Dien en de TRN Groep is 'afgeblazen', waarbij als reden werd opgegeven door Deloitte Dijker Van Dien dat 'de nieuwe combinatie te groot zou worden en daarom monopoloïde trekken zou gaan vertonen' (NRC, 5 oktober 1989). Dat een dergelijke 'monopolie'situatie van diensten die wettelijk verplicht afgenomen moeten worden maatschappelijk en voor grote ondernemingen in het algemeen zeer ongewenst is, behoeft nauwelijks geadstrueerd te worden. De positie van het management (en de Raad van Commissarissen) wordt bij problemen met de controlerende accountant van welke aard dan ook een onaangename omdat zij in haar wisselingsmogelijkheden steeds meer wordt beknot. 


\section{MAB}

De mate van efficiency van een accountantskantoor kan verder afgelezen worden aan de duur van de relatie met een cliënt. Een accountantskantoor raakt bekend met de organisatie van de cliënt en haar werkomgeving hetgeen de efficiency kan bevorderen.

Los hiervan kan de relatie met de accountant worden gecontinueerd vanwege een brok loyaliteit, tevredenheid met de geboden diensten in het verleden of uit pure inertie. Een andere reden om niet van accountant te wisselen heeft betrekking op het feit dat met de huidige accountant afspraken zijn gemaakt omtrent de waarderingsgrondslagen en de methode van winstbepaling. Indien een nieuwe accountant wordt ingehuurd is het mogelijk dat de door de cliënt toegepaste waarderingsgrondslagen en methode van winstbepaling niet acceptabel zijn voor de nieuwe accountant.

Een laatste reden die genoemd kan worden om niet van accountant te veranderen is dat de aandeelhouders (en de Raad van Commissarissen) vertrouwd zijn met het feit dat een bepaald accountantskantoor de controle verricht. Een verandering van accountant wordt dan door de aandeelhouders met argusogen bekeken en kan worden geïnterpreteerd als een teken dat het management op een bepaald terrein niet correct heeft gehandeld.

\section{ad 3 De reputatie van de cliënt}

Managers (of hun opvolgers) overwegen een ander accountantskantoor te vragen indien hun reputatie wordt aangetast. De reputatie van een manager wordt beschadigd als sprake is van:

1 openbaring van fraude, misleidende financiële berichtgeving of onwettige handelingen;

2 een accountantsverklaring bij de jaarrekening, die een niet goedkeurend karakter heeft;

3 een slechte 'performance'.

Ten aanzien van punt 1 geldt dat managers of hun opvolgers het nodige in het werk zullen stellen om de controle te verbeteren en het vertrouwen van de aandeelhouders (in de financiële rapportage) te herstellen.

Het zal duidelijk zijn dat het afgeven van een verklaring door de accountant, die niet goedkeurend is, een negatief licht werpt op het functioneren van het management en kan leiden tot wisseling van accountant. Door de wisseling van accountantskantoor kan het management wellicht ondanks het gebruikelijke collegiaal overleg - een goedkeurende verklaring verkrijgen waardoor zijn imago verbetert.

Een cliënt die in ernstige financiële problemen is geraakt heeft een nog grotere prikkel om van accountant te wisselen omdat daardoor wellicht meer mogelijkheden worden geschapen om het imago van het management (tijdelijk) op niveau te houden. Blijkens onderzoek in de USA (Schwartz, 1982) voeren ondernemingsleidingen vaker winstverhogende stelselwijzigingen door en wisselen vaker van accountant in tijden van financiële teruggang dan in tijden dat het goed gaat met de onderneming. Dit alles vooral in de hoop dat daardoor slecht nieuws niet in de externe verslaggeving behoeft te worden opgenomen.

Voorts blijkt uit onderzoek in de USA dat cliënten met financiële problemen veelal binnen een termijn van drie jaar voordat zij failliet gaan van accountant zijn gewisseld (Schwartz en Menon, 1985).

\section{Enkele empirische resultaten van onderzoek naar de redenen en frequentie van wisseling van accountantskantoor}

Op basis van de gegevens die The Accountant tweewekelijks c.q. maandelijks verstrekt omtrent wisseling van accountantskantoor en de beweegredenen daarvoor door ondernemingen in de UK hebben wij een overzicht samengesteld (zie overzicht 1).

Voorts hebben we - op basis van de gegevens van De Accountant - geconstateerd dat het aantal wisselingen van accountantskantoor met als reden concurrerend bod, voorstel of bureaupresentatie in 1988 relatief ten opzichte van de andere redenen gestegen is. Voorts blijken de cliënten veelal bij wisseling van accoumtant te kiezen voor een groter accountantskantoor, hetgeen een bevestiging blijkt te zijn voor de theorie van DeAngelo en Klein, Crawford en Alchian. De redenen zijn gezien de sterke invloed van GrootBrittannië voor Nederland wel indicatief. Repre- 


\section{MAB}

Overzicht 1: De belangrijkste redenen om van accountantskantoor te wisselen in de U.K. voor de jaren 1987 en 1988.

\begin{tabular}{|c|c|c|}
\hline \multirow{2}{*}{$\begin{array}{l}\text { Redenen om van accountantskantoor } \\
\text { te wisselen }\end{array}$} & \multicolumn{2}{|c|}{ Frequentie } \\
\hline & $n$ & $\%$ \\
\hline $\begin{array}{l}\text { Overname van een onderneming door de } \\
\text { huidige cliënt }\end{array}$ & 146 & 33,4 \\
\hline $\begin{array}{l}\text { Concurrerend bod, voorstel of bureaupre- } \\
\text { sentatie }\end{array}$ & 111 & 25,4 \\
\hline Contact van vennoot met nieuwe cliënt & 22 & 5,1 \\
\hline $\begin{array}{l}\text { Contacten tussen accountantskantoor en } \\
\text { nieuwe cliënt }\end{array}$ & 27 & 6,2 \\
\hline $\mathrm{Na}$ advisering controle-opdracht gekregen & 11 & 2,5 \\
\hline $\begin{array}{l}\text { Overgang naar een groot accountantskan- } \\
\text { toor }\end{array}$ & 10 & 2,3 \\
\hline Op aanbeveling van banken, advocaten & 15 & 3,5 \\
\hline Als gevolg van een management buy-out & 12 & 2,8 \\
\hline Roulering van accountantskantoor & 3 & 0,1 \\
\hline Rationalisatie/reorganisatie & 5 & 1,2 \\
\hline Overige redenen & 31 & 7,2 \\
\hline \multirow[t]{2}{*}{ Geen vermelding van de reden } & 45 & 10,3 \\
\hline & 438 & 100 \\
\hline
\end{tabular}

Bron: The Accountant, jaargang 1987 en 1988, no. 5211 (maart 1988) was ten tijde van het onderzoek niet beschikbaar.

sentatief behoeven zij echter niet te zijn. Hiervoor is nader onderzoek nodig.

Uit onderzoek naar de wisseling van accountantskantoor in Nederland voor de ter beurze genoteerde ondernemingen met een doorlopende notering (exclusief financiële instellingen) blijkt ten aanzien van het tijdvak 1971-1986 dat $84 \%$ van deze ondernemingen niet van accountantskantoor is gewisseld (Dijksma, Swarte en Langendijk in: Dijksma, 1988, p. 6). Slechts twee ondernemingen wisselden in deze periode tweemaal van accountantskantoor.

Voorts is geconstateerd dat een aantal wisselingen van accountant tot stand komt enkele jaren voordat een onderneming zijn beursnotering verliest.

\section{Samenvatting}

In dit artikel zijn een aantal redenen aangedragen waarom het management een bepaald accountantskantoor kiest c.q. voordraagt. Vervolgens is ingegaan op de problematiek van de wisseling van accountantskantoor. Voorts is geconstateerd dat bij grote ter beurze genoteerde ondernemingen in Nederland een grote trouw bestaat met betrekking tot het controlerende accountantskantoor. Wisselingen komen eigenlijk sporadisch voor. Zorgwekkend is de ontwikkeling dat het management van met name grote ondernemingen in Nederland nu en zeker in de toekomst bij een eventuele voortduring van de fusiegolf bij accountantskantoren niet of nauwelijks mogelijkheden overhoudt om van accountant te wisselen. Een situatie die vanuit velerlei oogpunt vragen oproept. Gelukkig lijkt binnen een aantal geledingen van het accountantsberoep het besef te zijn doorgedrongen dat een verdere samensmelting van grote kantoren maatschappelijk ongewenste gevolgen kan hebben. De fata morgana met betrekking tot het kunnen wisselen van accountantskantoor lijkt dan ook voorlopig verdwenen. De kring van accountantskantoren waaruit (middel)grote ondernemingen kunnen kiezen is echter betrekkelijk klein.

\section{Literatuur}

American Institute of Certified Public Accountants, Commission on Auditors' Responsibilities: Report, Conclusions and Recommendations, AICPA, 1978

Asbeck van G. en T. Buijtendorp. Fusieproces accountants hapert, NRC 5 oktober 1989.

Belle, L. H., Grondslagen der accountancy, 2e druk, Delwel Uitgeverij B.V., Den Haag, 1961.

DeAngelo, L. E., Auditor Independence, 'Low balling', and Disclosure Regulation, Journal of Accounting and Economics, no. 3, 1981, p. 113-127.

Dekker, H. C. en H. P. A. J. Langendijk, De beheersing van de (kosten van) accountantscontrole in Nederland, Maandblad voor accountancy en bedriffshuishoudkunde, september 1986 , p. 326-343.

Deloite, Haskins and Sells, An Opinion Survey of the Public Accounting Profession no. 401, 1978.

Dijksma, J., H. J. J. Swarte en H. P. A. J. Langendijk, Algemene gegevens over het onderzochte databestand, in Jaar in Jaar uit 3, red. J. Dijksma, Wolters Noordhoff, Groningen, 1989.

Dopuch, N. en D. Simunic. The Nature of Competition in the Auditing Profession: A Descriptive and Normative View, in: J. W. Buckley en J. F. Weston, red., Regulation and the Accounting Profession, Lifetime Learning, 1980. 
Francis, J. R., The Effects of Audit Firm Size on Audit Prices: A Study of the Australian Market, Journal of Accounting and Economics, August 1984, p. 133-151.

Francis, J. R. en D. T. Simon, A Test of Audit Pricing in the Small-Client Segment of the US Audit Market, The Accounting Review, January 1987, p. 145-157.

Francis, J. R. en E. R. Wilson, Auditor Changes: a Joint Test of Theories Relating to Agency costs and Auditor Differentiation, The Accounting Review, no. 4, October 1988, p. 663-682.

Jensen, M. C. en W. H. Meckling, Theory of the Firm: Managerial Behavior, Agency Costs, and Ownership Structure, Journal of Financial Economics, October 1976, p. 305-360.

Klein, B. R.. R. G. Crawford en A. Alchian, Vertical Integration, Appropriable Rents and the Competitive Contracting Process, Journal of Law and Economics, October 1978, p. 297-326.

Klein, B. R. en K. Leffler, The Role of Market Forces in Assuring Contractual Performance, Journal of Political Economy, August 1981, p. 615-641.

Langendijk, H. P. A. J., De onafhankelijkheid van de externe accountant vanuit een 'agency theory' perspectief, in: Organisaties in het web van hun omgeving, red. A. B. Dorsman en A. Huizing, Vermande, Lelystad, 1989.

Langendijk, H. P. A. J., Wisseling van accountantskantoor, in: Praktijk Register Accountants '89/'90, Delwel Uitgeverij B.V., Den Haag, 1989.

Limperg Instituut, Opvattingen over accountants, Limperg Instituut, Amsterdam, 1987.

Palmrose, Z., Audit Fees and Auditor Size: Further Evidence, Journal of Accounting Research, Spring 1986, p. 97-110.

Palmrose, Z., An Analysis of Auditor Litigation and Audit Service Quality, The Accounting Review, January 1988, p. 55-73.

Ramaer, J., De accountants, Quote, no. 2, februari 1988, p. 3445.

Schilder, A., Onderzoekt alles .... Over theorie en onderzoek van accountantscontrole, Wolters Noordhoff, Groningen, 1989.

Schwartz, K., Accounting Changes by Companies Facing Possible Insolvency, Journal of Accounting, Auditing and Finance, Fall 1982, p. 32-43.

Schwartz, K. en K. Menon, Auditor Switches by Failing Firms, The Accounting Review, April 1985, p. 248-261.

The Accountant, jaargangen 1987 en 1988 behalve March 1988.

Williams, D. D., The potential determinants of auditor change, Journal of Business Finance and Accounting, 15(2) Summer 1988, p. 243-261.

\section{Noten}

1 De auteur is dank verschuldigd aan Prof. Dr. A. J. Bindenga voor zijn opmerkingen bij een eerdere versie van het artikel. De verantwoordelijkheid voor de inhoud blijft volledig bij de auteur. 2 Onderzoek in Nederland op dit terrein wordt bemoeilijkt omdat ondernemingen in Nederland, in tegenstelling tot de USA, UK en Australië, niet verplicht zijn om hun accountantskosten als afzonderlijk bedrag in de jaarrekening op te nemen. Zie tevens Schilder 1989, p. 30.

3 Arthur Andersen heeft de hoogste omzet per werknemer en
Walgemoed de laagste (Ramaer, 1986). Het is slechts een grove maatstaf omdat een veelheid van factoren van invloed kan zijn. Arthur Andersen Nederland verricht bijvoorbeeld relatief veel meer adviesdiensten dan controlediensten in vergelijking met andere kantoren.

4 Uit onderzoek van Dekker en Langendijk (1986) blijkt dat bij bijna $50 \%$ van de respondenten/ondernemingen ontevredenheid bestaat over het functioneren van de controlerende accountant. 5 In Nederiand voltrekt zich een ware fusiegolf onder accountantskantoren die in onderstaand schema naar voren is gebracht.

Overzicht van fusies binnen de groep van 21 grootste accountantskantoren werkzaam op de Nederlandse accountancy-markt vanaf 1984 tot eind 1989

Gefuseerd:

$\mathrm{KKC}$

Moret \& Limperg

Dijker \& Doornbos

TRN Groep (NAM)

Dechesne van den Boom

Camps Obers

Bakker Versteegh

Niet gefuseerd:

Paardekooper en Hoffman

Berk Groep

Price Waterhouse

Walgemoed \& Co.

Arthur Andersen

VB Accountantskantoor

1 Een klein deel van het accountantskantoor Reyn de Blaey (kantoor Rotterdam) is niet samengegaan met Moret \& Limperg. $2 \mathrm{Er}$ is een samenwerkingsverband tussen Coopers \& Lybrand en Bakker Versteegh. Van een volledige fusie kan (nog) niet worden gesproken.

Ergo, het aantal grote en middelgrote accountantskantoren is in vijf jaar gehalveerd. 